Revista Española de Antropología Americana ISSN: 0556-6533

https://doi.org/10.5209/REAA.63699

\title{
La manufactura de los objetos de jadeíta verde imperial de las ofrendas del Templo Mayor de Tenochtitlan ${ }^{1}$
}

\author{
Hervé V. Monterrosa Desruelles²
}

Recibido: 27 de septiembre de 2018 / Aceptado: 16 de noviembre de 2018

Resumen. En el antiguo recinto sagrado de Tenochtitlan se han recuperado poco más de trescientos objetos de jadeíta verde imperial en diversas ofrendas distribuidas en todas las etapas constructivas del edificio. A través del análisis tecnológico, justificado con la arqueología experimental, se realizó el estudio traceológico de las huellas de manufactura con la finalidad de identificar la posible procedencia cultural de aquellos jades y determinar cuáles fueron manufacturados por artesanos mexicas.

Palabras clave: mexicas; jadeíta; tecnología; procedencia; estilo.

\section{[en] The Manufacture of Imperial Green Jadeite Objects in Offerings from the Great Temple of Tenochtitlan}

\begin{abstract}
A little more than three hundred green imperial jadeite objects have been excavated from Tenochtitlan's ancient sacred premises, from a variety of offerings spanning all the building's construction periods. Thanks to technological analysis, in accordance with experimental archeology, we were able to study the manufacturing hallmarks, with the goal of identifying those jade stones' possible cultural origins, and to determine which ones were manufactured by Mexica artisans.
\end{abstract}

Keywords: Mexica; jadeite; technology; provenance; style.

Sumario. 1. Introducción. 2. Los objetos de jadeíta verde imperial del Templo Mayor de Tenochtitlan. 3. Arqueología experimental y traceología en el análisis tecnológico. 4. El análisis tecnológico de los objetos de jadeíta verde imperial. 5. Discusión. 6. Conclusiones. 7. Referencias.

Cómo citar: Monterrosa Desruelles, Hervé V. 2018. «La manufactura de los objetos de jadeíta verde imperial de las ofrendas del Templo Mayor de Tenochtitlan». Revista Española de Antropología Americana 48: 211-231.

\section{Introducción}

Las jadeítas de color verde, en especial las de cromática más intensa designadas coloquialmente como «verde imperial», «verde esmeralda» y «verde manzana», formaron parte de las gemas semipreciosas más apreciadas en Mesoamérica durante la mayor parte del periodo prehispánico por su valor simbólico y por ser un mineral cuyos yacimientos se restringen únicamente al valle de Motagua, en Guatemala.

\footnotetext{
1 Se agradece al CONACYT y a Ciencia Básica su apoyo económico a través del proyecto CB-283896.

2 Escuela Nacional de Antropología e Historia, México. hmdesruelles@yahoo.fr
} 
Es muy conocida la maestría que alcanzaron los antiguos lapidarios mayas en el trabajo de esta piedra a lo largo del periodo Clásico (250-900 d.C.) y cuya explotación alcanzó su punto culminante durante el Clásico Terminal (600-900 d.C.), para decaer en los siglos subsecuentes. Conforme nos alejamos del área maya, la presencia de objetos de jadeíta se vuelve particularmente escasa y este es un rasgo característico que perduró desde aquellas épocas hasta el Posclásico (900-1521 d.C.). Dicho fenómeno es visible en las ofrendas del Templo Mayor de Tenochtitlan, lo cual es relevante ya que este edificio constituía el centro ideológico y político de la sociedad tenochca y, en consecuencia, es el lugar donde se esperaría encontrar una mayor cantidad de objetos elaborados con este bien suntuario. Sin embargo, aunque está presente en todas las épocas del huey teocalli, este aluminosilicato de sodio (NaAlSi2O6) es significativamente escaso y presenta poca variabilidad formal con respecto a otros materiales. Lo anterior sugiere que los mexicas no mantenían el control de su circulación y tampoco existen evidencias que nos permitan conocer si este material llegaba bajo la forma de materia prima, objetos terminados procedentes de regiones lejanas o, como sugería Thouvenot (1982: 177-178), como preformas.

El problema anterior no había sido posible de resolver con la simple observación macroscópica de patrones estilísticos diagnósticos, ya que, aunque algunos de los objetos presentan rasgos iconográficos identificables que permiten atribuirles una filiación cultural, ya sea maya o mexica, muchas de las piezas son objetos «geométricos», como por ejemplo cuentas, a los que no es posible asignarles un origen o una pertenencia a determinada cultura.

Para resolver este problema se recurrió al análisis tecnológico, cuya metodología estuvo supeditada a la arqueología experimental y al uso de técnicas arqueométricas, con el propósito de identificar patrones no visibles, como las trazas o huellas de manufactura dejadas por determinado tipo de herramientas diagnósticas con las que se elaboraron dichos objetos.

El presente texto sintetiza una parte de los resultados obtenidos en mi tesis doctoral intitulada La presencia maya en el Templo Mayor de Tenochtitlan. El análisis tecnológico de los objetos de jadeita verde imperial (Monterrosa 2018), que contó con el apoyo de CONACyT. Dicha investigación formó parte del proyecto Estilo y Tradiciones Tecnológicas del México Antiguo dirigido por el Dr. Emiliano Melgar del Museo del Templo Mayor. La colección analizada incluyó los objetos recuperados durante las temporadas de campo dirigidas por el Dr. Eduardo Matos Moctezuma y algunos salvamentos realizados por el Programa de Arqueología Urbana.

\section{Los objetos de jadeíta verde imperial del Templo Mayor de Tenochtitlan}

\subsection{Exploración visual}

Ante el amplio universo de piedras verdes que existen en las ofrendas del Templo Mayor, se estableció un primer nivel de observación macroscópico, con ayuda de una lupa de 10 a $15 x$, para una identificación preliminar de los objetos de jade. El propósito de este paso fue el de identificar lo que en geología se denomina acabado vítreo (Silva y Mendoza 2013: 139), que es característico de la jadeíta.

La jadeíta no es un mineral que pueda identificarse a simple vista con facilidad, ya que puede lucir distintos tonos de color que pueden incluir verde, gris, blanco, 


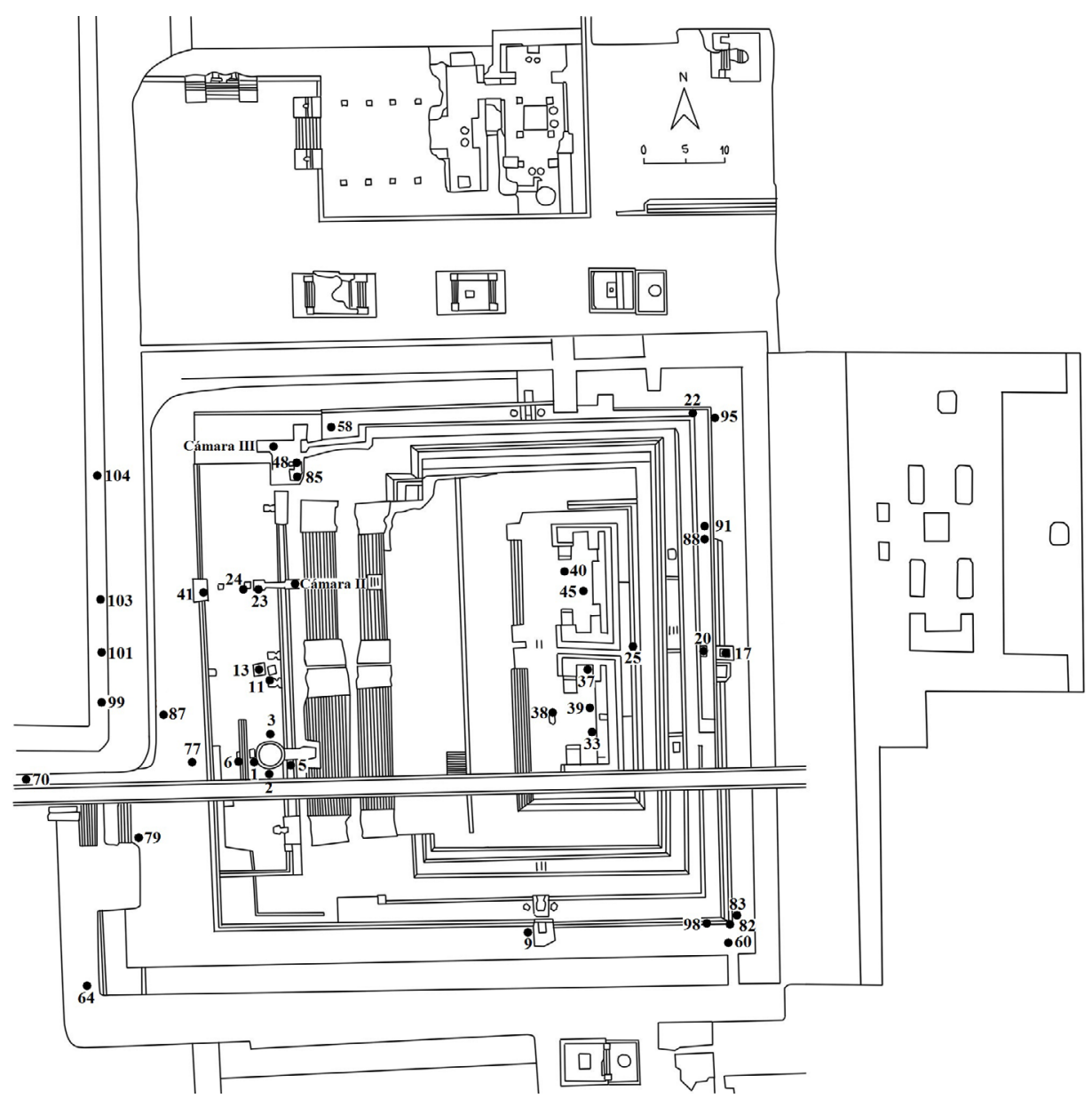

Figura 1. Dibujo en planta del Templo Mayor de Tenochtitlan y localización de las ofrendas con objetos de jadeíta verde imperial (dibujo de Víctor Solís).

azul, rosa, morado y negro. El presente estudio se centra únicamente en los objetos de jadeíta con colores verdes más intensos, a los cuales se les conoce ordinariamente como «verde imperial», «verde esmeralda» y «verde manzana», variantes cromáticas que forman parte de un mismo conjunto colorimétrico que, por sus características visuales, los mexicas apreciaban por igual. No obstante, dichas categorías apelan a analogías que forman parte de la experiencia personal de cada persona y no designan con precisión el matiz al que se hace referencia. Ante ese panorama, el uso de una base de datos colorimétricos sistematizada es lo más recomendado, pues permite determinar dichas variantes cromáticas de forma confiable y reproducible, es decir, implanta un parámetro de control inequívoco que no está sujeto a las percepciones subjetivas ni a un lenguaje coloquial (Gerharz et al. 1988: 88). Con la finalidad de ordenar la nomenclatura de los colores verdes referidos líneas arriba con valores de comparación, se recurrió al empleo de la Munsell Rock Color Book (2013), lo que permitió definir rangos específicos de color y determinar los valores 5G 6/6 Brilliant 
Cuadro 1. Relación espacio-temporal de las ofrendas del Templo Mayor

\begin{tabular}{llll}
\hline $\begin{array}{c}\text { Etapa } \\
\text { constructiva }\end{array}$ & \multicolumn{1}{c}{$\begin{array}{c}\text { Periodo } \\
\text { histórico }\end{array}$} & \multicolumn{1}{c}{ Ofrendas } & \multicolumn{1}{c}{ Tlatoani } \\
\hline II & $1345-1426$ d.C. & $\begin{array}{l}33,37,38,39,40,45 \\
\text { Segundas escalinatas de la etapa II }\end{array}$ & $\begin{array}{l}\text { Acamapichtli } \\
\text { Huitzilihuitl } \\
\text { Chimalpopoca } \\
\text { Itzcóatl }\end{array}$ \\
III & $1427-1440$ d.C. & 25 & Moctezuma Ilhuicamina \\
IVa & $1440-1469$ d.C. & 48,85, cámara III & Axayácatl \\
IVb & $1469-1481$ d.C. $1,2,3,5,6,9,11,13,17,20,22,23,24$, \\
& $41,58,60,82,83,88,91,95,98$, cámara II & \\
V & $1481-1486$ d.C. 77 & Tízoc \\
VI & $1486-1502$ d.C. $70,79,87,101,103,104$ & Ahuízotl \\
VII & $1502-1520$ d.C. 64,99 & Moctezuma Xocoyotzin \\
\hline
\end{tabular}

Green para el verde imperial, 5G 5/6 Moderate Green para el verde esmeralda y 10GY 6/4 Yellowish Green para el verde manzana.

Cabe precisar que la jadeíta no es un mineral heterogéneo, por lo que es frecuente la presencia de impurezas que resultan en variaciones de color o manchas en un mismo objeto ${ }^{3}$. Sin embargo, se consideraron todas las piezas que tuvieran los tonos verde más brillantes, incluso cuando sólo estuvieran presentes en una mínima proporción. Bajo esta norma, se contabilizó un total de 305 objetos de jade verde imperial distribuidos en las ofrendas de siete etapas constructivas que abarcan un periodo de tiempo comprendido entre 1345 d.C. y 1521 d.C. (Cuadro 1; Figura 1).

\subsection{Distribución y diversidad formal}

En el Cuadro 2 se presenta la distribución temporal de los objetos de jade verde imperial y se puede observar que existe una disparidad aparente entre las diferentes épocas; sin embargo, esto se debe al estado de conservación de los vestigios arqueológicos, los cuales han soportado un constante proceso de destrucción desde la época de la Conquista hasta su hallazgo en 1978. Las ofrendas de las etapas IVa y $\mathrm{IVb}$ son las que mayor cantidad de objetos han arrojado por su sobresaliente estado de conservación y por contar con un mayor número de intervenciones arqueológicas.

Desde la perspectiva formal, $4 / 5$ partes de los objetos son cuentas $(n=245)$ y, en menor medida, pendientes ( $\mathrm{n}=33), 9$ tapas de orejera, 6 orejeras, 1 pectoral, 5 placas esgrafiadas, 2 remates de cetro, 3 piezas en proceso de manufactura y 1 no identificado. Llama la atención la exigua variedad tipológica de los objetos de jade, en especial porque, siendo un material tan apreciado, se esperaría un mayor aprovechamiento de este recurso.

Son pocos los ejemplares con rasgos estilísticos culturales claramente mayas, como un fragmento de pendiente con un rostro maya de perfil y otro de frente y dos pendientes que representan a un pauahtun y una placa de personaje con tocado de serpiente. Por su parte, sólo dos objetos presentan elementos estilísticos mexicas:

\footnotetext{
3 La visualización del acabado vítreo y la sistematización colorimétrica son dos métodos de exploración que sirvieron también como una aproximación preliminar en el reconocimiento de la jadeíta con fines de identificación y caracterización. Ello significa que deben ser complementados forzosamente con técnicas de composición elemental o química como la espectrometría EDS, MicroRaman y XRF, por mencionar unos ejemplos; aunque este aspecto no se aborda en el presente texto (véase Monterrosa y Melgar 2017).
} 
un pendiente con forma de Tláloc y un pectoral circular que representa un anáhuatl (Figura 2). En contraste, todos los demás objetos tienen formas «geométricas» sin

Cuadro 2. Distribución de objetos de jadeíta verde por etapa constructiva

\begin{tabular}{llcc}
\hline $\begin{array}{c}\text { Etapa } \\
\text { constructiva }\end{array}$ & \multicolumn{1}{c}{ Periodo histórico } & Número de objetos & \% de la colección \\
\hline II & Pre-imperial & 24 & 7,87 \\
III & Pre-imperial & 2 & 0,65 \\
IVa & Consolidación del imperio & 35 & 11,48 \\
IVb & Consolidación del imperio & 207 & 67,87 \\
V & Imperio tenochca & 4 & 1,31 \\
VI & Imperio tenochca & 21 & 6,89 \\
VII & Imperio tenochca & 12 & 3,93 \\
\hline
\end{tabular}
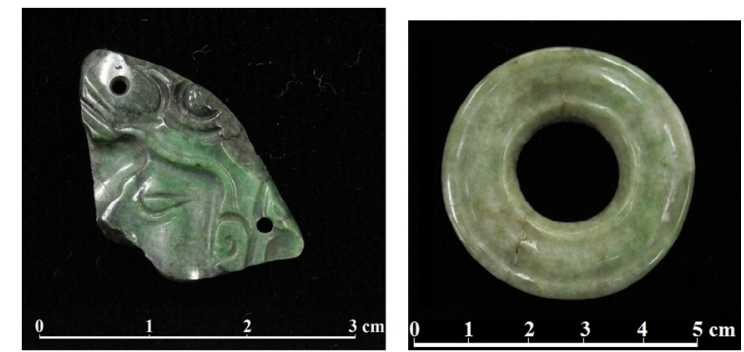

Figura 2. Objetos con rasgos estilísticos mayas: placa con rostro maya de perfil y pendiente con rostro (izquierda); y mexicas: pectoral con forma de anáhuatl y pendiente mexica (derecha). (Fotografías de Hervé Monterrosa).
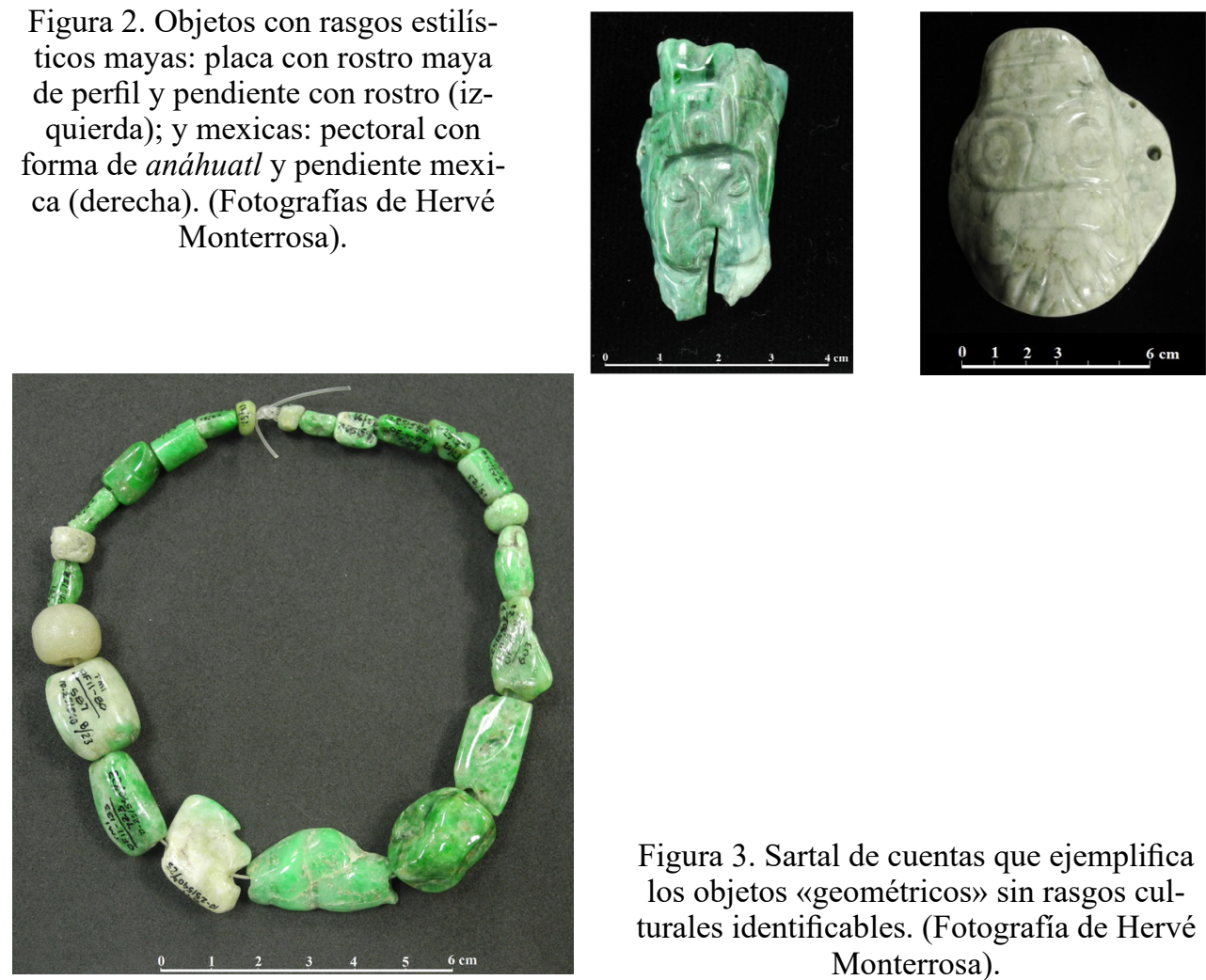

Figura 3. Sartal de cuentas que ejemplifica los objetos «geométricos» sin rasgos culturales identificables. (Fotografía de Hervé Monterrosa). 
rasgos estilísticos diagnósticos que permitan determinar su pertenencia cultural (Figura 3).

\section{Arqueología experimental y traceología en el análisis tecnológico}

La metodología empleada en la identificación de los estilos tecnológicos con los que fueron manufacturados los objetos de jadeíta, estuvo conforme a la establecida en el proyecto La lapidaria del Templo Mayor: estilos y tradiciones tecnológicas (Melgar 2014: 236), dirigido por el Dr. Emiliano Melgar adscrito al Museo del Templo Mayor, el cual cuenta, además, con su propio taller de arqueología experimental en lapidaria. Los lineamientos metodológicos de dicho proyecto se inspiran de los propuestos por el Dr. Adrián Velázquez (2007) para su taller de arqueología experimental en concha dentro del proyecto Arqueología experimental en materiales conquiológicos y Técnicas de manufactura de los objetos de concha del México Prehispánico (Melgar 2004: 20-22; 2014: 235), también del Museo del Templo Mayor.

\subsection{Uso de la arqueología experimental}

Con la finalidad de comprender el empleo de la arqueología experimental en el análisis tecnológico realizado a los objetos de jadeíta verde, cuya meta fue el de identificar la manufactura de los objetos arqueológicos y su probable filiación cultural, es importante hacer mención - de forma sucinta- a algunos puntos que dan justificación al uso de esta herramienta metodológica. Hay que enfatizar que la arqueología experimental brinda un potencial parcial acerca de cómo pudieron haber sido hechas las cosas (Gibaja 1993: 10), ya que no es posible conocer la realidad pretérita en su totalidad.

Ante la falta de información relativa a las herramientas, las técnicas y las formas de producción utilizadas en la manufactura de bienes lapidarios, la arqueología experimental ofrece instrumentos que permiten esclarecer estas lagunas y generar propuestas alternativas acerca de las diferentes manifestaciones culturales en el trabajo de piedras preciosas o semi-preciosas. En este sentido, dado que nuestro estado de conocimiento acerca de la lapidaria mesoamericana es escueto, la experimentación se consolida como la opción más viable para generar datos acerca de la producción de objetos antiguos. Según Robert Ascher, uno de los promotores de la arqueología experimental (Frère et al. 2004: 109), los experimentos imitativos son una parte substancial de la arqueología experimental porque permiten poner a prueba suposiciones que atañen a las formas de comportamiento de sociedades pretéritas frente a sus propias tecnologías, contribuyendo a la solución de problemas generados por las limitaciones del dato arqueológico (Ascher 1961: 793-794). En este sentido, la replicación es una alternativa para conocer, al menos de una forma aproximada, los procesos de manufactura y los tiempos empleados (Fernández González 2000: 108). Existen desde luego otros factores importantes que inciden en las formas de producir artefactos y que la experimentación por sí sola no resuelve, tales como los factores sociales relacionados con la organización del trabajo y las condiciones materiales de la producción (López y Nieto 1985: 36). Estos aspectos deben de ser tomados en cuenta por el investigador en el momento de interpretar sus resultados y de conformidad con el contexto histórico y social del que proceden los objetos. 
Sin embargo, no siempre se cuenta con esa información. En el caso específico del Templo Mayor, la información que nos brindan los artefactos se restringe exclusivamente a contextos de ofrendas y no de talleres y/o basureros, por lo que no se cuenta con los indicadores directos de la producción, como son las materias primas, herramientas, desechos, objetos en proceso de elaboración y piezas terminadas (Melgar 2014: 235). Para subsanar este vacío, se parte del supuesto de que la experimentación imitativa es un intento para examinar una determinada creencia sobre el comportamiento cultural, entendiendo que todas las actividades humanas están reguladas por patrones o normas (Radcliffe-Brown 1940: 8; Ascher 1961: 803 y 806). Un patrón debe ser entendido como un modelo, una guía o un procedimiento que el artesano debe seguir para elaborar objetos (Ascher 1961: 804) y proporcionarles características específicas (Melgar 2014: 235); como resultado, toda esta normatividad queda plasmada dentro del objeto (Ascher 1961: 803). La arqueología experimental es entonces una construcción y ello es posible siempre y cuando existan los elementos suficientes que permitan una reconstrucción acertada (Reynolds 1994: 3). Por lo tanto, si el objetivo del experimentador es reconstituir estas normas, deberá elegir materiales acordes con aquellos que estaban disponibles dentro del contexto de la sociedad estudiada (Ascher 1961: 809; Mirambell 1994: 109) y, si bien no todos los materiales y métodos deben ser auténticos, al menos sí aquellos pertinentes a la hipótesis (Outram 2008: 2).

Para ello, la Nueva Arqueología considera a la arqueología experimental y a la etnografía como teorías de rango medio que permiten partir de la observación de hechos actuales, adquirir información válida y aplicarlos a la realidad arqueológica (Binford 1977: 6; Velázquez 2007: 23; Frère et al. 2004: 98). Esto significa que la analogía es la única forma ${ }^{4}$ de entender las dinámicas del pasado (Ascher 1961: 807) debido a que es el «proceso mental gracias al cual conferimos a cierto elemento una determinada característica, por compartir otras que conocemos» (Velázquez 2007: 23; Vicente 2010: 98); ello significa que se proyecta la observación de una situación establecida a otra (Frère et al. 2004: 99). No obstante, para el caso específico del análisis tecnológico de la lapidaria mesoamericana, el punto de partida más confiable son los indicadores de evidencias de producción reportados en distintos contextos arqueológicos, pues aportan datos fidedignos que delimitan la selección y la pertinencia de los materiales a emplear durante la experimentación.

Al proceder con el empleo de herramientas, pasos y gestos técnicos antiguos a través de simulaciones o duplicaciones se deben obtener resultados idénticos que deben ser comparados con los artefactos arqueológicos (Reynolds 1994: 2; Frère et al. 2004: 110; Velázquez 2007: 23; Melgar 2014: 235). Lo anterior se cimenta en el criterio uniformista (Binford 1977: 7), según el cual «el empleo de una herramienta particular, hecha de un determinado material, usada de manera específica en ciertas condiciones, dejará rasgos característicos y diferenciables» (Velázquez 2007: 23). Esta característica está en estrecha relación con las leyes de causa y efecto que per-

\footnotetext{
4 Investigadores anteriores consideraron que la naturaleza de los experimentos puede guiarse a través de supuestos basados en el sentido común y la experiencia práctica del investigador (Ascher 1964: 807). Esto es particularmente válido cuando no se cuenta con muchas fuentes de información referencial. No obstante, este tipo de planteamientos deben ser tomados con mucha cautela, ya que forman parte de la realidad subjetiva del experimentador. Un dato curioso y particularmente ejemplar de esto fue la afirmación de A. Langenscheidt (2006: 55-60) acerca del uso de diamante o arenas diamantíferas como abrasivo entre los lapidarios mesoamericanos, cuando no existen yacimientos confirmados de éstos en Mesoamérica.
} 
miten inferir las circunstancias específicas y las formas de hacer las cosas (Frère et al. 2004: 101). Las características físicas y químicas de las materias primas condicionan la manufactura de objetos, tanto en su maleabilidad como en las huellas que deja cada material (op. cit.) que, desde la perspectiva de la Física, tiene que ver con la estructura cristalina de determinado mineral. En nuestro caso, por ejemplo, lo que asemeja una jadeíta a otra es el arreglo de sus átomos de $\mathrm{NaAlSi}_{2} \mathrm{O}_{6}$ y esto es válido para cualquier otra roca como, por ejemplo, la piedra caliza, la obsidiana o el pedernal. No hay que perder de vista, sin embargo, que todo mineral viene mezclado con otros elementos, a modo de impurezas, por lo que es importante verificar variaciones significativas en las medidas y la textura de las trazas.

\subsection{La traceología}

La arqueología experimental tiene como meta simular, reproducir y duplicar tecnologías pasadas, manufacturas y usos con el objetivo de entender patrones de conducta cultural a través de las huellas encontradas (Ascher 1961: 793; Lewenstein 1987: 7; Gibaja 1993: 11; Solís 2011: 162). La traceología es una disciplina analítica central en aquellas investigaciones cuya metodología está supeditada a la arqueología experimental enfocada a la identificación de huellas de uso o de manufactura generadas sobre artefactos (Fernández González 2000: 109; Martín 2008: 15). Fundado por Semenov (1964: 2) y desarrollado en gran medida por la arqueología prehistórica, en la actualidad este campo de investigación se ha centrado en estudios funcionales (Vicente 2010: 98, 103) y, más recientemente, en estudios tecnológicos enfocados en la manufactura de objetos. El aporte de este investigador soviético consistió en realizar experimentos controlados en rocas y demostrar, con ayuda de la observación microscópica, la reminiscencia de patrones de trazas de manufactura y de uso hasta en las piedras más duras en artefactos experimentales y la contrastación de dicha información con el registro arqueológico (Mansur-Franchomme 1986: 20-21, 75; 1991; Gibaja 1993: 11; Mirambell 1994: 107; Vicente 2010: 98). Esto permitió alcanzar nuevos niveles de explicación acerca de la funcionalidad del utillaje prehistórico (Gutiérrez 1990: 18), al relacionar la observación de huellas arqueológicas con los factores que las generaron a través de las muestras experimentales. En este sentido, con la microscopía de bajos aumentos se pudieron identificar marcas de desgaste en los bordes de los artefactos, por lo que fue posible establecer, incluso, una tipología para los distintos tipos de huellas y funciones (desconchado y embotamiento, etc...).

A través de la experimentación, los prehistoriadores han buscado entender los aspectos tecnológicos y los traceológicos de determinados objetos, es decir, cómo fue hecho el objeto y de qué manera fue usado (Martín Lerma y Avezuela 2008: 81). Las huellas son efectos tecnológicos de carácter macroscópico y microscópico que fueron dejados en los artefactos durante los procesos de su manufactura (Keeley 1980: 25) y de su uso (Mirambell 1994: 107). La traceología es, entonces, «la única metodología que nos conduce a la comprensión de la función del utillaje lítico» (Gutiérrez 1990: 46) y/o de las formas en que se elaboraron objetos lapidarios. Lo anterior gravita en la experimentación porque enseña al experimentador la comprensión de un gesto y las huellas resultantes y, además, le permite obtener una base de datos con la que comparar los objetos arqueológicos (Gutiérrez 1990: 21). En este sentido, el gesto y la herramienta son marcas de fábrica y la función de la experimentación es 
la de comprender los procesos productivos y el pensamiento técnico de sociedades pretéritas (Morin 2013: 41).

De esta forma, el análisis de las huellas experimentales (traceología) permite dilucidar los mecanismos de transformación deliberados que intervienen sobre una materia prima desde los procesos de manufactura hasta la posible función de un objeto (Gibaja 1993: 11; Martín y Avezuela 2008: 81).

\section{El análisis tecnológico de los objetos de jadeíta verde imperial}

\subsection{Base epistemológica}

Desde la perspectiva epistemológica, se partió de diversas fuentes de información con el objetivo de determinar las herramientas y los procesos de elaboración de los objetos de jadeíta del Templo Mayor; conocimientos que, además, sentaron las bases para el desarrollo de la metodología experimental. Con base en lo anterior, en el taller de lapidaria dirigido por el Dr. Emiliano Melgar, se han realizado hasta la fecha más de 500 experimentos que han logrado reproducir los diversos tipos de modificaciones visibles en los objetos lapidarios, como desgastes, cortes, perforaciones, incisiones, percusiones, calados y acabados en distintos tipos de rocas preciosas o semipreciosas (obsidiana, jadeíta, travertino, turquesa, serpentina, mármol, calcita, ónix, crisocola, amazonita, pizarra, mica, pirita, azabache, cristal de roca) que, según los contextos arqueológicos, sabemos que fueron empleadas en la época prehispánica (Melgar 2014: 236).

En primer lugar, documentos históricos como los de Fray Diego Durán (1967) y Sahagún $(1975,1979)$ aportaron datos relevantes, pero sucintos, acerca del tipo de utensilios empleados, como herramientas sólidas para desbastar, cortar, perforar y pulir, así como herramientas indirectas como lo son arenas para abrasivos. Estos cronistas también señalan algunas de las regiones de donde podían provenir las materias primas y los materiales con los que se elaboraban las herramientas (Figura 4).

Sin duda, lo que aportó una mayor cantidad de datos fidedignos son las evidencias arqueológicas recuperadas en contextos de talleres y las evidencias indirectas
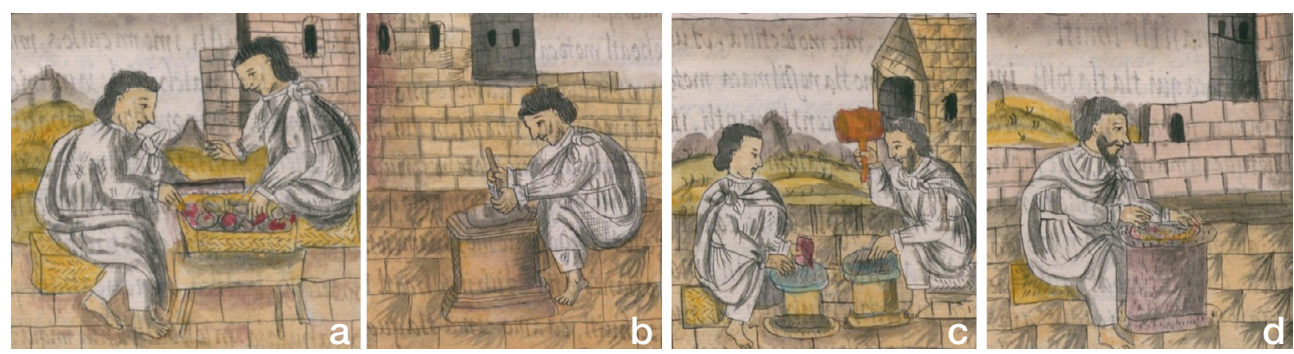

Figura 4. Artesanos con sus herramientas y técnicas de trabajo: a) artesano lapidario aserrando una piedra; b) artesano posiblemente sosteniendo un ótlatl para perforar;

c) lapidario, al parecer, percutiendo una piedra; d) artesano lapidario raspando una piedra sobre una laja espolvoreada con partículas que se interpretan como arena, lo que puede significar que se encuentra en el proceso de desgaste o pulido de la pieza (Códice Florentino, Sahagún 1979, Tomo 3, fojas 55v y 56r). 


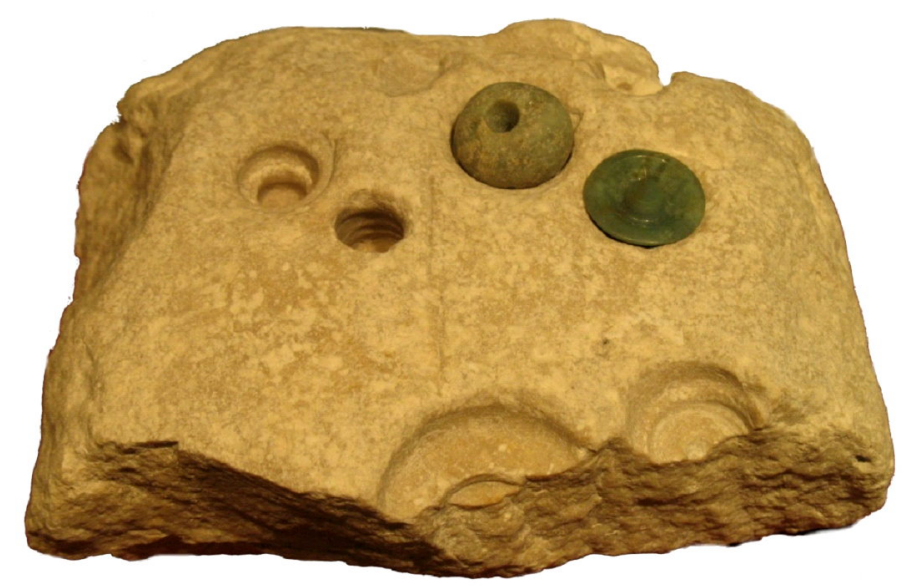

Figura 5. Laja de caliza para desgastar procedente del sitio de Naachtún, Guatemala. (Fotografía de Emiliano Melgar).

de producción asociadas al trabajo de la jadeíta. Casi la totalidad de dichos talleres arqueológicos han sido localizados en el área maya en sitios del Clásico Tardío; entre los más relevantes están los de las Tierras Altas de Guatemala, donde destacan decenas de sitios situados en las riberas del río Motagua, especialmente en el área de San Agustín Acasaguastlan (véase Smith y Kidder 1943; Feldman et al. 1975; Walters 1981; Rochette 2009a, 2009b; Rochette y Pellecer 2008) y los sitios localizados en el curso superior del río El Tambor, afluente del Motagua (Taube et al. 2006; Callejas 2008). Los talleres más célebres son los que fueron excavados en Cancuén, en el Petén guatemalteco (Kovacevich 2006, 2007, 2011; Andrieu y Forné 2010). Por su parte, el sitio preclásico de Nativitas, en Tlaxcala, es el único con evidencias de talleres de jadeíta que ha sido localizado en el Altiplano Central de Mexico (Hirth et al. 2009). En muchos sitios como Tikal (Moholy-Nagy 1997: 300-310), Calakmul (Domínguez y Folan 1999), Nakum, Copán y Caracol, se han encontrado objetos en proceso, desechos y herramientas en escondites y rellenos constructivos, aunque no se han localizado todavía los correspondientes talleres.

Entre los indicadores de producción de todos estos sitios destacan bloques y pedacería de jadeíta, preformas, así como cuentas, hachas y algunos pendientes en proceso de elaboración. De mayor relevancia fueron las herramientas encontradas como, por ejemplo, lajas de caliza (Figura 5) o basalto para desgastar, punzones de pedernal para perforar o nódulos de jadeíta para pulir, así como núcleos de perforación que sugieren el uso de abrasivos como polvo de obsidiana o pedernal; sin embargo, no es posible detectar este tipo de evidencias en contexto arqueológico por tratarse de partículas muy finas.

\subsection{EI análisis tecnológico}

De los 305 objetos que conforman la colección de jades verde imperial del Templo Mayor, se seleccionó una muestra de 54 objetos para el estudio tecnológico, tomando en consideración la variabilidad formal (cuentas, pendientes, etc...) e incluyendo objetos con rasgos estilísticos mayas y mexicas. Con base en la información obtenida a través de las fuentes históricas y los contextos arqueológicos, se realizaron los experimentos con diferentes herramientas sobre jadeíta del Motagua. Los resultados 
Cuadro 3. Tipos de modificaciones y herramientas empleadas sobre jadeíta

\begin{tabular}{ll}
\hline \multicolumn{1}{c}{ Modificación } & \multicolumn{1}{c}{ Herramientas } \\
\hline Desgastes de superficies & Basalto, andesita, riolita, arenisca, caliza y granito, adicionando \\
& agua y ocasionalmente arena. \\
Cortes & Arena, agua y tiras de piel o cuerdas vegetales. \\
& Herramientas líticas de pedernal y obsidiana. \\
Perforaciones & Abrasivos (arena, ceniza volcánica, polvo de obsidiana y polvo \\
& de pedernal), animados con ramas de carrizo, adicionando agua. \\
& Herramientas líticas de pedernal y obsidiana. \\
Calados & Abrasivos (arena, ceniza volcánica, polvo de obsidiana, polvo \\
& de pedernal y polvo de cuarzo), animados con ramas de carrizo \\
& de gran diámetro, adicionando agua. \\
Incisiones & Herramientas líticas de pedernal y obsidiana. \\
Acabados & Pulido con abrasivos, agua y trozos de piel. \\
& Bruñidos con trozos de piel en seco. \\
& La aplicación de ambos acabados. \\
\hline
\end{tabular}

permitieron obtener distintas huellas de manufactura, las cuales se compararon con los objetos arqueológicos del Templo Mayor de Tenochtitlan (Cuadro 3). Para dicho análisis se establecieron tres niveles de observación (Velázquez 2007):

- El nivel macroscópico, que consiste en una exploración visual in situ del objeto experimental y arqueológico, que puede apoyarse con el uso de una lupa de hasta 20x.

- Microscopía estereoscópica. Con aumentos de 10x y 30x, permite observar y fotografiar (acoplando una cámara digital) con mayor detalle las huellas de las piezas, poniendo el énfasis en su dirección, su relieve y la textura de la superficie. Este nivel de observación es preliminar, pues permite descartar o confirmar el uso de cierto tipo de herramientas y procesos de manufactura.

- Microscopía Electrónica de Barrido (MEB). Con este instrumento se han obtenido los mejores resultados para caracterizar y distinguir las huellas producidas por cada tipo de herramienta. Las muestras experimentales y arqueológicas se observan a 100x, 300x, 600x, 1000x y, en algunos casos, hasta 4000x, obteniendo las respectivas imágenes digitales para ser interpretadas posteriormente 5 .

Las huellas de manufactura se caracterizan en función de las siguientes variables:

1. La estructura cristalina del objeto.

2. Las características superficiales como rugosidad, alisamiento, irregularidad, porosidad y presencia de partículas.

\footnotetext{
5 La ventaja del MEB es que no requiere la presencia en físico del objeto arqueológico o la muestra experimental ya que se opta la impresión de polímeros, que consiste en el uso de un polímero replicante para obtener las huellas de manufactura. Esté método no destructivo consiste en reblandecer con una gota de acetona industrial un segmento de polímero que se aplica inmediatamente sobre la superficie de la modificación que se quiere analizar; después de algunos segundos se seca y vuelve a endurecerse, con lo que se obtiene el molde de la huella. Antes de ser colocados en el MEB, los polímeros deben ser recubiertos por iones de oro para una mayor conductividad de la muestra con el haz de electrones.
} 
Cuadro 4. Características de las huellas observadas con el

Microscopio Estereoscópico (10X Y 30X)

\begin{tabular}{|c|c|c|}
\hline $\begin{array}{l}\text { Modificación que se } \\
\text { quiere ver }\end{array}$ & Si lo que se observa tiene... & Entonces es... \\
\hline Modificación & Características de las trazas & Herramienta empleada \\
\hline Desgaste & Superficie con rayones rectos bien marcados & Instrumento lítico \\
\hline Desgaste & Superficie con textura rugosa & Instrumento lítico + abrasivo \\
\hline Corte e incisión & $\begin{array}{l}\text { Incisión y bordes con líneas paralelas bien } \\
\text { marcadas. }\end{array}$ & Instrumento lítico \\
\hline Perforación & $\begin{array}{l}\text { Perforación con círculos concéntricos bien } \\
\text { marcados. }\end{array}$ & Perforador lítico \\
\hline Perforación & $\begin{array}{l}\text { Perforación con bordes lisos y sin evidencia } \\
\text { de líneas }\end{array}$ & Abrasivo + carrizo \\
\hline Perforación & Perforación con presencia de bulbo & Abrasivo + carrizo \\
\hline Pulido/Bruñido & $\begin{array}{l}\text { Superficie lustrosa y con evidencias de des- } \\
\text { gaste atenuados }\end{array}$ & Piel \\
\hline
\end{tabular}

Cuadro 5. Características de las huellas observadas con el Microscopio Electrónico de Barrido (100X, 300X, 600X y 1000X)

\begin{tabular}{|c|c|}
\hline Tipo de huella & Características \\
\hline Bandas & Franjas rectas evidentes que pueden tener de 2 a $100 \mu \mathrm{m}$ de grosor. \\
\hline Líneas & Rayas o estrías rectas evidentes menores a $2 \mu \mathrm{m}$ de grosor. \\
\hline Líneas difusas & Rayas rectas atenuadas y poco perceptibles. \\
\hline Partículas & $\begin{array}{l}\text { Aglomerados con bordes irregulares que presentan tamaños que pueden osci- } \\
\text { lar entre } 0,5 \text { y } 100 \mu \mathrm{m} \text {. Están agrupados de manera indefinida. }\end{array}$ \\
\hline Superficie aplanada & $\begin{array}{l}\text { Superficie regular, aplanada en el que se pueden observar las huellas difusas } \\
\text { de modificaciones anteriores, es decir, de pasos previos en la cadena opera- } \\
\text { tiva. Ejemplo de ello pueden ser las huellas de desgaste que pueden aparecer } \\
\text { atenuadas por efecto del proceso de pulido y bruñido. }\end{array}$ \\
\hline
\end{tabular}

3. El aspecto de las huellas (líneas, bandas o texturas) (Cuadro 4) y sus medidas aproximadas en micras $(\mu \mathrm{m})$ (Cuadro 5).

En relación con las superficies, a simple vista y con el microscopio estereoscópico, se observó que la mayoría de los objetos presentan una superficie muy lustrosa que podría definirse como vítrea y sobre la cual se extienden pequeños rayones tenues muy finos. Por su parte, las dos piezas con iconografía mexica, es decir, el Tláloc de la Ofrenda 41 y el anáhuatl, tuvieron un acabado muy lustroso, aunque no vítreo; además, se pudieron apreciar rayones mucho más marcados que en los demás objetos.

Con el MEB, en la mayoría de los objetos se identificaron bandas de $20 \mu \mathrm{m}$ de grosor atravesadas por líneas de $4 \mu \mathrm{m}$ que experimentalmente coinciden con los desgastes realizados con una laja de caliza. En contraste, el pendiente Tláloc y el pectoral anáhuatl presentaron una superficie lisa con bandas aplanadas de $100 \mu \mathrm{m}$ de ancho que se extienden en varias direcciones y se entrecruzan; este patrón guardó similitud con los desgastes realizados en laja de basalto. Sin embargo, el anáhuatl presentó también un segundo patrón de huellas que consistió en sucesiones de bandas de $10 \mu \mathrm{m}$ de grosor y líneas finas sobre una superficie rugosa, que fueron muy similares a las que se obtuvieron experimentalmente con una laja de arenisca; estas últimas trazas se empalman por debajo de las huellas de basalto (Figura 6). 

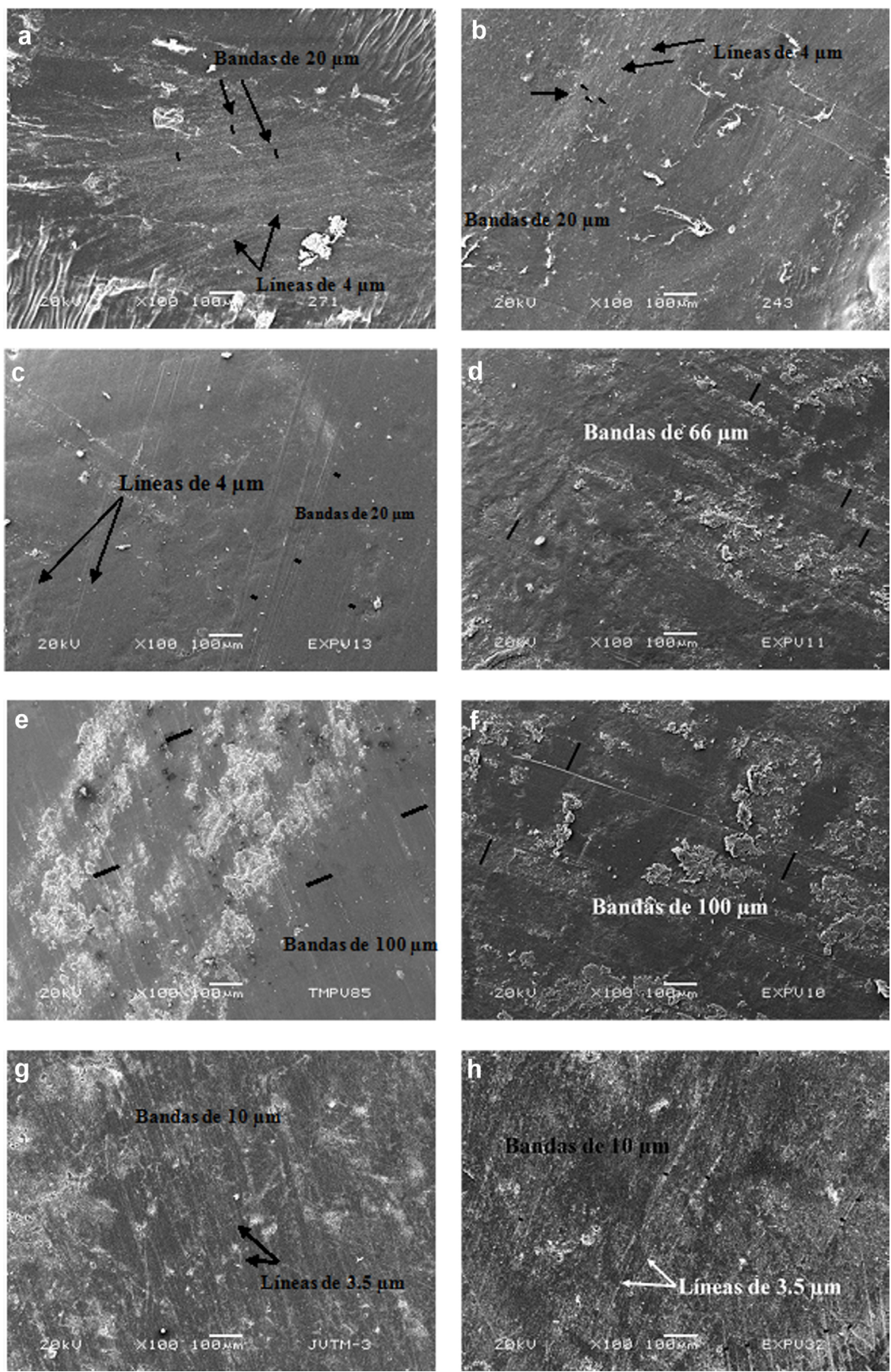

Figura 6. Análisis tecnológico de superficies a 100x de una cuenta de la Ofrenda 60 (a) y una tapa de la Ofrenda 33 y (b) y su comparación con desgastes experimentales con caliza (c) y (d). Pendiente Tláloc de la Ofrenda 41 (e) comparado con la experimental con basalto (f). Pectoral anáhuatl de la Ofrenda 17 (g) y junto con la experimental con arenisca (h). (Micrografías de Gerardo Villa, Emiliano Melgar y Hervé Monterrosa). 
Los acabados fueron más difíciles de determinar ya que, por la dureza de la jadeíta, las huellas de los pulidos y los bruñidos se sobreponen a las de los desgastes. Por tal razón, para esta modificación se emplea el mayor aumento (1000x). Casi la totalidad de los objetos mostraron una textura de partículas cruzada por líneas difusas de 1 a $2 \mu \mathrm{m}$ de ancho que guardaron similitud con los pulidos experimentales hechos con nódulo de jadeíta y bruñido con piel. Por su parte, el pendiente Tláloc de la Ofrenda 41 presentó líneas rectas-paralelas entrecruzadas y rugosas que miden entre 0,6 y $2 \mu \mathrm{m}$ de grosor; no obstante, hasta la fecha no se ha identificado la herramienta empleada para esta modificación.

Los cortes e incisiones presentaron dos patrones. Con ayuda del microscopio óptico, en algunos objetos se observaron rayones rectos muy finos, dispuestos de forma paralela, mientras que en otras piezas se apreciaron estrías paralelas mucho más gruesas. A través del MEB fue posible determinar que el primer tipo de huellas presentaba líneas finas y rectas distanciadas entre $0,6 \mu \mathrm{m}$ y $1,3 \mu \mathrm{m}$ que se extienden sobre una textura rugosa de partículas; dicha característica concuerda con los cortes experimentales hechos con lascas de obsidiana. El segundo patrón se vio como bandas rectas-paralelas alternadas, de entre $2 \mu \mathrm{m}$ y $4 \mu \mathrm{m}$ de espesor, y entre las cuales pueden hallarse micro-rayados que coincidieron con las huellas obtenidas en cortes experimentales hechos con lascas de pedernal (Figura 7).

Las perforaciones presentaron mayor dificultad al verlas en el microscopio óptico ya que muchas alcanzaron a ser pulidas en una gran parte del orificio; sin embargo, en algunos objetos pudieron identificarse líneas concéntricas muy tenues que sugirieren
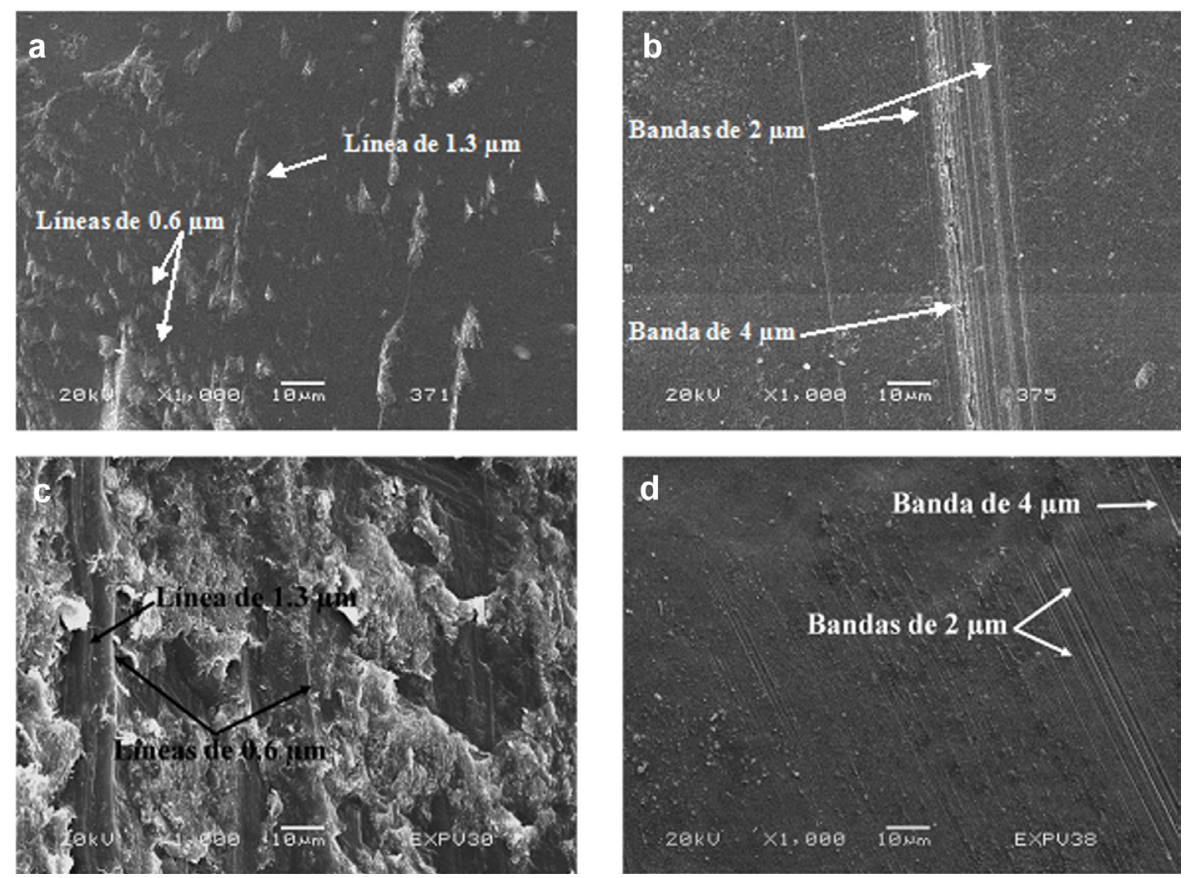

Figura 7. Análisis tecnológico de incisiones a 1000x de dos cuentas de las Ofrendas 79 (a) y 103 (b) y su comparación con incisiones experimentales con lasca de obsidiana (c) y pedernal (d). (Micrografías de Gerardo Villa, Emiliano Melgar y Hervé Monterrosa). 
el uso de una herramienta sólida. En otras piezas se observó una superficie lisa con textura esmerilada que sugiere el uso de algún tipo de abrasivo; en este último caso, un limitado número de cuentas tenía presente una pequeña protuberancia al fondo de la perforación, lo que parece sugerir el uso de una herramienta hueca que sirvió de vehículo para el abrasivo. En el caso de la herramienta sólida, el MEB permitió ver bandas paralelas de $2 \mu \mathrm{m}$ a $4 \mu \mathrm{m}$ de espesor dispuestas de manera concéntrica con micro-rayados internos que, por su similitud con las huellas experimentales, se determinó que se elaboraron con lasca de pedernal. Por su parte, las perforaciones con aspecto esmerilado presentaron una textura rugosa con líneas difusas de 1 a 1,5 $\mu \mathrm{m}$ de grosor sobre una textura uniforme, huellas muy similares a las experimentales obtenidas con el empleo de polvo de pedernal y un carrizo.

En síntesis, el Cuadro 6 muestra los cuatro patrones de trazas distintos que se identificaron a partir del estudio tecnológico.

Cuadro 6. Patrones tecnológicos distinguidos a partir del estudio tecnológico

\begin{tabular}{llllll}
\hline \multicolumn{1}{c}{ Patrón } & \multicolumn{1}{c}{ Desgastes } & Incisiones & \multicolumn{1}{c}{ Cortes } & Perforaciones & \multicolumn{1}{c}{ Acabados } \\
\hline I & Caliza & Obsidiana & Obsidiana & Pedernal & Jadeíta \\
II & Caliza & Pedernal & Pedernal & Pedernal & Jadeíta \\
III & Arenisca & Obsidiana & - & - & No identificado \\
IV & Basalto & Obsidiana & - & Pedernal & No identificado \\
\hline
\end{tabular}

\section{Discusión}

Los resultados del análisis tecnológico sugieren una estandarización en casi todos los objetos que conformaron la muestra $(\mathrm{n}=54)$ salvo en dos casos: el pendiente Tláloc de la Ofrenda 41 y el pectoral anáhuatl de la Ofrenda 17.

\subsection{Pertenencia cultural de los patrones tecnológicos I y II}

En los patrones I y II, que constituyen la mayor parte de los objetos analizados, los desgastes y la regularización de los bordes fue realizada por medio de lajas o metates de piedra caliza; sin embargo, lo que distingue a ambos estilos es el uso diferenciado de herramientas de obsidiana (I) y pedernal (II) para la elaboración de cortes e incisiones. En los ejemplares analizados, la mayoría de los objetos presentaron el uso de obsidiana en cortes $(n=6)$ e incisiones $(n=14)$ y pocos de pedernal $(n=1$ y $n=5$, respectivamente). Respecto a la perforaciones y horadaciones, en todas las piezas se empleó pedernal; no obstante, en la mayoría se utilizó como abrasivo bajo la forma de polvo animado con carrizo $(n=48)$ y muy pocos con un buril $(n=2)$. En ambos patrones los acabados fueron realizados con nódulo de jadeíta y bruñidor de piel.

Comparando los resultados del análisis tecnológico con las evidencias de producción encontradas en talleres y otros contextos de varios sitios de las Tierras Bajas Mayas y los talleres de la región del Motagua medio, se desprende que la mayoría de los objetos del Templo Mayor provinieron del área maya. Las herramientas diagnósticas que sostienen nuestra hipótesis son el desgastador de piedra caliza, que es una roca abundante en toda la península de Yucatán y las Tierras Bajas, y el pulidor de jadeíta. 
Cabe señalar que, hasta hace poco, las lajas de piedra caliza con los negativos de cuentas y orejeras funcionaban como pulidores, avanzándose incluso algunas propuestas que hicieron el esfuerzo de determinar el tipo de objetos que pudieron ser elaborados con dicha herramienta (Landry 2013); sin embargo, aquella hipótesis quedó en un nivel especulativo que no fue más allá de meras descripciones morfológicas. En cambio, a través de la arqueología experimental se pudo determinar el patrón de las trazas características de la piedra caliza para diferenciarlas de otras herramientas.

Los resultados obtenidos coincidieron con los de diversos objetos de jadeíta procedentes de varios sitios mayas como Palenque, Cancuén, Tikal, El Zotz, El PerúWaká (Melgar y Andrieu 2016: 270-276), Calakmul, Naachtun, Izamal, Champotón, Tenam Puente, Conkal, la Corona y Xcambó, lo cual confirmó una manufactura maya de los objetos de jade del Templo Mayor.

Asimismo, se compararon las huellas identificadas en jades y cuarcitas recuperados en Tamtoc, jadeítas de Teopancazco (Teotihuacan) y los de Monte Albán, las cuales coincidieron también con herramientas reportadas en los talleres del área maya.

\subsection{Pertenencia cultural de los patrones tecnológicos III y IV}

El patrón III, identificado en el pendiente Tláloc y el pectoral anáhuatl de las respectivas Ofrendas 41 y 17, presenta desgastes con laja o metate de basalto e incisiones con lasca de obsidiana; con respecto al pulido, aún no se ha identificado experimentalmente la herramienta involucrada. Las características traceológicas concordaron con las de objetos lapidarios y conquiológicos considerados propiamente tenochcas del periodo imperial (Melgar 2014: 298; Velázquez y Melgar 2006: 302-306), como, por ejemplo, objetos de obsidiana y mármol del Templo Mayor y los edificios aledaños (Solís 2015: 184), cuyos patrones tecnológicos homogéneos reflejan una clara estandarización.

El pectoral anáhuatl de la Ofrenda 17 presenta, por un lado, huellas de desgaste con laja o metate de arenisca (patrón IV); sin embargo, éstas aparecen dispuestas debajo de otras que presentan el aspecto y las dimensiones que dejan los desgastadores de basalto (patrón III). La superposición de huellas de dos herramientas distintas sugiere que la pieza fue reciclada por los mexicas. Sin embargo, a partir de algunos estudios previos, es factible proponer, al menos de forma preliminar, dos posibles estilos tecnológicos relacionados con el uso de arenisca en desgastes. El primero, estaría relacionado con una manufactura olmeca de la Costa del Golfo, pues se ha identificado el empleo de arenisca en objetos lapidarios de diversos sitios olmecas presentes en el Museo de Antropología de Xalapa, de sitios olmecas más alejados como Chiapa de Corzo, así como en las piezas de jade azul ofrendadas en el Templo Mayor (Monterrosa y Melgar 2017: 908). El otro posible estilo de manufactura podría tener relación con los mayas de la Costa del Golfo, específicamente de Tabasco y una parte de Campeche, quienes también empleaban lajas o metates de arenisca (roca común en la región) para efectuar desgastes, según se ha identificado en materiales de sitios como Moral Reforma, Comalcalco, Calakmul y Jaina (Emiliano Melgar, comunicación personal). Por último, el análisis tecnológico realizado por Cuevas y Melgar (2016) a la parafernalia de la conocida como Reina Roja de Palenque también reveló el uso de desgastadores de arenisca y pulidores de piel en su manufactura, lo cual difiere de los metates o lajas de caliza y los bruñidores de 
jadeíta empleados por los lapidarios palencanos. Basándose en esos resultados, los autores plantean la posibilidad de que esta monarca de Palenque provenía de algún sitio de la Costa del Golfo y, como una forma de reforzar su identidad, ostentó piezas elaboradas en su región de origen.

Los datos obtenidos a través del análisis tecnológico sugieren que la mayor parte de los objetos que llegaron al Huey Teocalli de Tenochtitlan fueron reliquias mayas del Clásico, pues ello coincide con la información que nos brindan las evidencias de talleres lapidarios de jadeíta fechados para el Clásico Tardío. No se descarta que algunos objetos provinieran de pueblos contemporáneos a los mexicas como los k'iche' de Utatlan, en las Tierras Altas de Guatemala, o de sitios de las Tierras Bajas del norte como, por ejemplo, Mayapan. No obstante, aún falta realizar estudios traceológicos en la lapidaria de sitios posclásicos mayas, con los cuales sería posible establecer una base comparativa. Los análisis de Proskouriakoff (1974) en los materiales de jade del Cenote Sagrado de Chichén Itzá sugieren que, desde el Posclásico Temprano, los mayas recuperaban objetos de jadeíta de sitios de las Tierras Bajas del Sur para recuperarlas como reliquias, lo cual indica que desde esta época la industria del jade estaba en declive. En el sitio posclásico tardío de La Campana, en Mixco Viejo, se encontraron pocos objetos de jadeíta entre la parafernalia de los artesanos ahí sepultados, lo que sugiere que la explotación de jadeíta en el Motagua ya estaba en decadencia.

\section{Conclusión}

El desarrollo del análisis tecnológico apoyado por la arqueología experimental ha dado buenos resultados en el discernimiento de estilos de manufactura de la lapidaria mesoamericana. En el presente caso, las evidencias de producción en talleres lapidarios o en otros contextos arqueológicos fueron, sin duda, la base epistemológica más fidedigna, pues sienta las bases para la reproducción de los procesos de manufactura con herramientas similares. Al caracterizar y comparar las huellas de manufactura de las muestras experimentales con las arqueológicas del Templo Mayor con ayuda de la microscopía óptica y la microscopía electrónica de barrido, se diferenciaron tres patrones de manufactura. Estos pudieron ser identificados mediante la comparación de materiales de jade verde imperial procedentes de diversos sitios de las Tierras Bajas mayas del Clásico, de la Costa del Golfo, así como de otros objetos elaborados en Tenochtitlan.

A partir de los resultados alcanzados con el análisis tecnológico, se desprenden nuevos planteamientos para el futuro acerca del nivel de control que ejercieron los mexicas o los mayas contemporáneos sobre el jade verde imperial y sus rutas de aprovisionamiento. A pesar de haber sido un bien suntuario muy apreciado, el número de objetos en el Huey Teocalli es muy escaso y casi la totalidad de los mismos fueron elaborados bajo estándares tecnológicos ajenos a la cuenca de México.

\section{Referencias}

Andrieu, Chloé y Mélanie Forné. 2010. «Producción y distribución del jade en el mundo maya: talleres, fuentes y rutas de intercambio en su contexto interregional vista desde 
Cancuén», en XXIII Simposio de Investigaciones Arqueológicas en Guatemala, 2009, Bárbara Arroyo, Adriana Linares y Lorena Paiz, eds., pp. 946-955. Guatemala: Museo Nacional de Arqueología y Etnología

Ascher, Robert. 1961. «Experimental Archaeology». American Anthropologist 63 (4): 793-816. Binford, Lewis R. 1977. "General Introduction», en For Theory Building in Archaeology. Essays on Faunal Remains, Aquatic Resources, Spatial Analysis, and Systemic Modeling, Lewis R. Binford, ed., pp. 1-10. Albuquerque: Academic Press.

Callejas Martínez, Selket Susana. 2008. Los artefactos líticos del periodo Clásico en la cuenca del Motagua Medio. Tesis de licenciatura. Guatemala: Universidad de San Carlos de Guatemala.

Cuevas García, Marta y Emiliano Melgar Tísoc. 2016. «Análisis tecnológico de la manufactura de la máscara de la Reyna Roja de Palenque». Ponencia presentada en el $10^{\circ}$ Congreso Internacional de Mayistas. Los Mayas: discursos e imágenes de poder, 26 junio-2 julio 2016, Izamal, Yucatán, México

Domínguez Carrasco, María del Rosario y William J. Folan. 1999. «Hilado, confección y lapidación: los quehaceres cotidianos de los artesanos de Calakmul, Campeche, México», en XII Simposio de Investigaciones Arqueológicas en Guatemala, 1998, Juan Pedro Laporte y Hector L. Escobedo, eds., pp. 628-646. Guatemala: Museo Nacional de Arqueología y Etnología.

Durán, Fray Diego. 1967. Historia de las Indias de la Nueva España e islas de Tierra Firme. México: Editora Nacional.

Feldman, Lawrence H., Robert Terzuola, Payson Sheets y Constance Cameron. 1975. Jade Workers in the Motagua Valley. The Late Classic Terzuola Site. Columbia: University of Missouri.

Fernández González, Carlos. 2000. «De la comunicación arqueología-sociedad: el posible papel de la arqueología experimental». Nivel Cero: revista del grupo arqueológico Attica 8: 107-116.

Frère, María Magdalena, María Isabel González, Ana Gabriela Guráieb y Andrés Sebastián Muñoz. 2004. «Etnoarqueología, arqueología experimental y tafonomía», en Explorando algunos temas de arqueología, Ana M. Aguerre y José Luis Lanata, comps., pp. 97118. Buenos Aires: Universidad de Buenos Aires y Gedisa.

Gerharz, Rudolf Richard, Renate Lantermann y Dirk R. Spennemann. 1988. «Munsell Color Charts: A Necessity for Archaeologists?». Australian Journal of Historical Archaeology 6: 88-95.

Gibaja Bao, Juan Francisco. 1993. «El cómo y el porqué de la experimentación en análisis funcional». Revista de Arqueología 148: 10-15.

Gutiérrez Sáez, Carmen. 1990. «Introducción a las huellas de uso: los resultados de la experimentación». Espacio, Tiempo y Forma. Serie I. Prehistoria y Arqueología 3: 15-53.

Hirth, Kenneth G., Mari Carmen Serra Puche, Carlos Lazcano Arce y Jasón de León. 2009. «Intermittent Domestic Lapidary Production during the Late Formative Period at Nativitas, Tlaxcala, Mexico». Archeological Papers of the American Anthropological Association 19 (1): 157-173.

Keeley, Lawrence H. 1980. Experimental Determination of Stone Tool Use: A Microwear Analysis. Chicago: University of Chicago Press.

Kovacevich, Brigitte. 2006. Reconstructing Classic Maya Economic Systems: Production and Exchange at Cancuen, Guatemala. Tesis doctoral. Nashville: Vanderbilt University. . 2007. «Ritual crafting, and agency al the classic maya kingdom of Cancuen», en Mesoamerican Ritual Economy, Archaeological and Ethnological Perspectives, E. 
Christian Wells y Karla L. Davis-Salazar, eds., pp. 67-114. Boulder: University Press of Colorado.

. 2011. «The Organization of Jade Production at Cancuen, Guatemala», en The Technology of Maya Civilization: Political Economy and Beyond in Lithic Studies, Zachary X. Hruby, Geoffrey E. Braswell y Oswaldo Chinchilla Mazariegos, eds., pp. 151-163. Nueva York: Routledge Taylor y Francis Group.

Landry, Rachael Ruth. 2013. Ancient Maya Stone Polishers and Issues with the terminology for the Artifacts Polished with These Tools. Tesis de maestría. Orlando: University of Central Florida.

Langenscheidt, Adolphus. 2006. «Los abrasivos en Mesoamérica». Arqueología Mexicana 80: 55-60.

Lewenstein, Suzanne. 1987. Stone Tools at Cerros. The Ethnoarchaeological and Use-Wear Evidence. Austin: University of Texas Press.

López Aguilar, Fernando y Rosalba Nieto Calleja. 1985. «Comentarios sobre la arqueología experimental aplicada a la repetición de artefactos». Boletín de Antropología Americana 11: $35-37$.

Mansur-Franchomme, María Estela. 1986. Microscopie du matériel lithique préhistorique. Traces d'utilisation, altérations naturelles, accidentelles et technologiques. Exemples de Patagonie. Cahiers du Quaternaire 9. París: Centre Régional de Publications de Bordeaux, Centre National de la Recherche Scientifique.

-1991. «El análisis funcional de artefactos líticos: obsidiana», en Antropología y técnica 4, Luis Torres, ed., pp. 73-93. México: Instituto de Investigaciones Antropológicas, Universidad Nacional Autónoma de México.

Martín Lerma, Ignacio. 2008. «Análisis Microscópico de la industria lítica: la traceología». Panta Rei. Revista de ciencia y didáctica de la historia III: 15-25.

Martín Lerma, Ignacio y Bárbara Avezuela Aristu. 2008. «Tecnología y funcionalidad: dialogando con las trazas», en JIA 2008. Actas de las I Jornadas de Jóvenes en Investigación Arqueológica: dialogando con la cultura material, tomo I, pp. 81-86. Madrid: Compañía Española de Reprografía y Servicios.

Melgar Tísoc, Emiliano. 2004. Proyecto La Lapidaria del Templo Mayor: Estilos y tradiciones tecnológicas. México: Archivo del Museo del Templo Mayor. Manuscrito inédito.

- 2014. Comercio, tributo y producción de las turquesas del Templo Mayor de Tenochtitlan. Tesis doctoral. México: Universidad Nacional Autónoma de México.

Melgar Tísoc, Emiliano y Chloé Andrieu. 2016. «Informe del análisis tecnológico de objetos de jadeíta del El Perú Waká», en Proyecto Arqueológico Waka', Informe 13, Temporada 2015, Juan Carlos Pérez y Griselda Pérez, eds., pp. 265-280. Guatemala: Informe entregado a la Dirección General del Patrimonio Cultural y Natural. IDAEH.

Mirambell, Lorena. 1994. «Fundamentos sobre el estudio de huellas de uso en materiales líticos arqueológicos». Anales de Antropología 31: 105-131.

Moholy-Nagy, Hattula. 1997. «Middens, Construction Fill, and Offerings: Evidence for the Organization of Classic Period Craft Production at Tikal, Guatemala». Journal of Field Archaeology 24 (3): 293-313.

Monterrosa Desruelles, Hervé V. 2018. La presencia maya en el Templo Mayor de Tenochtitlan. El análisis tecnológico de los objetos de jadeita verde imperial. Tesis deoctoral. México: Escuela Nacional de Antropología e Historia.

Monterrosa Desruelles, Hervé V. y Emiliano Melgar Tísoc. 2017. «Reliquias mayas y olmecas de jadeíta en el Templo Mayor de Tenochtitlan», en XXX Simposio de Investigaciones Arqueológicas en Guatemala 2016, Bárbara Arroyo, Luis Méndez Salinas y Gloria 
Ajú Álvarez, eds., Tomo II, pp. 905-916. Guatemala: Museo Nacional de Arqueología y Etnología, Ministerio de Cultura y Deportes, Instituto de Antropología e Historia, Asociación Tikal.

Morin, Denis. 2013. «Archéologie et Histoire des techniques. Expérimenter le métal et le feu: la préhistoire du geste». Le Nouvel Éducateur, Revue de l'Institut Coopératif de l'École Moderne 211: 38-41. https://hal.archives-ouvertes.fr/hal-00794473.

Munsell Color. 2013. Munsell Rock Color Book. Washington, D.C.: Geological Society of America.

Outram, Alan K. 2008. «Introduction to experimental archaeology». World Archaeology 40 (1): 1-6.

Proskouriakoff, Tatiana. 1974. Jades from the Cenote of Sacrifice. Chichén Itzá, Yucatan. Cambridge: Peabody Musem of Archaeology and Ethnology, Harvard University.

Radcliffe-Brown, Alfred R. 1940. «On Social Structure». The Journal of the Royal Anthropological Institute of Great Britain and Ireland 70 (1): 1-12.

Reynolds, Peter J. 1994. «Experimental Archaeology. A Perspective for the Future», Reuvens Lecture 5, Stichting voor de Nederlande Archeologie. http://butser.org.uk/Exp\%20 Arch $\% 20$ A $\% 20$ perspective $\% 20$ for $\% 20$ the $\% 20$ Future.pdf.

Rochette, Erick T. 2009a. «Jade in Full: Prehispanic Domestic Production of Wealth Goods in the Middle Motagua Valley, Guatemala». Archeological Papers of the American Anthropological Association 19: 205-224.

- 2009b. The Late Classic Organization of Jade Artifact Production in the Middle Motagua Valley, Zacapa, Guatemala. Tesis doctoral. Pittsburgh: The Pennsylvania State University.

Rochette, Erik T. y Mónica Pellecer. 2008. «¿A quién está asociado?: La producción artesanal doméstica de bienes de estatus en la cuenca media del río Motagua», en XXI Simposio de Investigaciones Arqueológicas en Guatemala, 2007, Juan Pedro Laporte, Bárbara Arroyo y Héctor Mejía, eds., pp. 57-75. Guatemala: Museo Nacional de Arqueología y Etnología.

Sahagún, fray Bernardino de. 1975. Historia general de las cosas de Nueva España. México: Editorial Porrúa.

- 1979. Códice Florentino. El manuscrito 218-220 de la colección Palatina de la Biblioteca Medicea Laurenziana. 3 vols. México: Giunti-Barbéra, Archivo General de la Nación.

Semenov, Sergei A. 1964. Prehistoric Technology, an Experimental Study of the oldest tools and Artefacts from traces of Manufacture and Wear. Londres: Cory, Adams y MacKay.

Silva Romo, Gilberto y Claudia Cristina Mendoza Rosales, eds. 2013. Manual para el trabajo geológico de campo. México: DGAPA, Proyecto PAPIME PE-101909. Facultad de Ingeniería, Universidad Nacional Autónoma de México.

Smith, A. Ledyard y Alfred V. Kidder. 1943. Explorations in the Motagua Valley, Guatemala. Washington, D.C.: Carnegie Institution of Washington.

Solís Ciriaco, Reyna Beatriz. 2011. La producción de bienes de prestigio en concha de Tula Hidalgo. Tesis de maestría. México: Universidad Nacional Autónoma de México.

- 2015. Esferas de producción y consumo de la lapidaria de los edificios aledaños al Templo Mayor de Tenochtitlan. Tesis doctoral. México: Universidad Nacional Autónoma de México.

Taube, Karl A., Zachary X. Hruby y Luis Romero. 2006. Fuentes de jadeita y antiguos talleres: un reconocimiento arqueológico en el curso superior del río El Tambor, Guatemala. 
Informe entregado a la Foundation for the Advancement of Mesoamerican Studies, Inc. http://www.famsi.org/reports/03023es/03023esTaube01.pdf.

Thouvenot, Marc. 1982. Chalchihuitl. Le jade chez les Aztèques. París: Muséum National d'Histoire Naturelle, Institut d'Ethnologie, Musée de 1'Homme, Palais de Chaillot.

Velázquez Castro, Adrián. 2007. La producción especializada de los objetos de concha del Templo mayor de Tenochtitlan. México: Instituto Nacional de Antropología e Historia.

Velázquez Castro, Adrián y Emiliano Melgar Tísoc. 2006. «La elaboración de los ehecacozcatl de concha del Templo Mayor de Tenochtitlan», en Arqueología e historia del Centro de México, Homenaje a Eduardo Matos Moctezuma, Leonardo López Luján, David Carrasco y Lourdes Cué, eds., pp. 525-537. México: Instituto Nacional de Antropología e Historia.

Vicente Santos, Francisco José. 2010. «El estudio de las marcas de uso, un gran desconocido». El Futuro del Pasado. Revista electrónica de Historia 1: 97-107. http://www. elfuturodelpasado.com/ojs/index.php/FdP/article/view/9/10.

Walters, Gary Rex. 1981. «Proyecto Arqueológico San Agustín Acasaguastlán». Antropología e Historia de Guatemala 3: 325-369. 